\title{
FORMAÇÃO E APRENDIZAGEM NA DOCÊNCIA EM EDUCAÇÃO FÍSICA ESCOLAR
}

\author{
Rosana Dias Fraga \\ Prefeitura Municipal de Vitória, Vitória, Espírito Santo, Brasil \\ Zenólia Christina Campos Figueiredo \\ Universidade Federal do Espírito Santo, Vitória, Espírito Santo, Brasil
}

\begin{abstract}
Resumo
Busca-se compreender de que maneira os professores de Educação Física se constituem docentes no espaço escolar, em meio a diferentes sentidos e singularidades, considerando a escola como lócus privilegiado em que a docência se instaura. Este estudo foi protagonizado por 12 professores que atuam no Ensino Fundamental; utiliza três instrumentos na coleta de informações: o questionário, o memorial e a entrevista narrativa; e em meio às recorrências e às singularidades das narrativas, visualiza as temáticas de análise: a) construção da identidade profissional; b) formação e aprendizagem da docência; c) momento de prática em que docência se constrói; d) permanência e continuidade.
\end{abstract}

Palavras-chave: Educação Física. Formação. Aprendizagem Docente.

\section{Introdução}

A temática desse estudo é a constituição da identidade docente em Educação Física. $\mathrm{O}$ objetivo central foi compreender como ocorre a constituição docente dos professores de Educação Física no espaço escolar. Para tanto, buscamos falar da constituição e dos sentidos atribuídos à docência; de sua natureza, que é o ensino; do sujeito da ação pedagógica, o professor; da escola como lócus em que a docência se instaura; das relações que nela são estabelecidas entre os sujeitos que motivam o processo de ensino-aprendizagem, professores e alunos.

Dialogamos com 12 professores de Educação Física que atuam no Ensino Fundamental de um Sistema Municipal de Ensino, os quais narraram suas trajetórias e experiências vividas na constituição de sua condição de "ser professor", e que têm em comum o trabalho no contexto escolar. Abordamos aqui aspectos que nos chamaram a atenção nessas narrativas: a formação e a aprendizagem na docência, mediante a condição de ser professor de Educação Física do/no espaço escolar. 
A escola é o lócus privilegiado em que a docência se instaura, o que justifica a opção de pesquisa com professores de Educação Física, atuantes na regência de classe no Ensino Fundamental de um Sistema Municipal de Ensino.

Para selecionar os sujeitos, recorremos à Gerência de Recursos Humanos e solicitamos a listagem de professores de Educação Física efetivos, bem como as suas localizações de trabalho. O primeiro instrumento trabalhado com o universo de professores consistiu em um questionário no qual procurávamos identificar se a opção pelo curso de licenciatura em Educação Física ocorreu pela intenção de atuar no contexto formal de educação e, em caso negativo, identificar como esses professores se aproximaram do trabalho escolar, quais as suas perspectivas quanto à continuidade na carreira e como se (auto)percebiam profissionalmente.

Dos 112 professores de Educação Física atuantes que constavam na listagem, 67 responderam aos questionários. Realizada a análise desses questionários, identificamos 33 professores que se aproximavam do perfil delimitado: 23 deles ingressaram no curso, determinados a atuar na área escolar e 10 se identificaram com a idéia ao longo da formação inicial.

O passo seguinte foi a realização de uma reunião com os professores para explicar nossas intenções de pesquisa e propor-lhes, então, um segundo instrumento de coleta de dados: a redação de um memorial. Do total de 23 professores, 12 desenvolveram o memorial, que indicou a necessidade de recorrer a um terceiro instrumento de coleta de dados: a narrativa oral, experimentada por meio de uma entrevista, com elementos do que se intitula 'entrevista narrativa' (TEIXEIRA; PÁDUA, 2006).

Fizemos uma análise do memorial e das respostas dos respectivos questionários entregues, para elaborar as questões da entrevista. Terminadas as transcrições, o passo seguinte foi devolvê-las aos professores, conforme havíamos combinado, para que a validassem. Essa devolução foi feita em mãos e nas respectivas escolas.

Após esse período de coleta de informações, que durou aproximadamente sete meses, percorremos mais uma vez as escolas, solicitando aos professores a autorização formal para usar as informações que nos foram confiadas no decorrer da pesquisa, a fim de dar início ao processo de análise. Todos assinaram os termos de consentimento e escolheram nomes fictícios que seriam utilizados no relatório da pesquisa.

Foi possível compreender que a condição de ser professor desponta em todos as narrativas, perpassando diferentes períodos de sua vida, orientada especialmente pelos conhecimentos advindos dos processos formativos institucionais (formação inicial e continuada); das experiências que antecederam tais processos (como as vivências de alunos/atletas/praticantes das atividades corporais); da busca individual pelo conhecimento (autoformação); das trocas estabelecidas com pessoas próximas (na escola e fora dela); dos saberes da profissão e do exercício cotidiano da prática docente.

Em meio às recorrências e às singularidades das narrativas dos professores, conseguimos visualizar algumas temáticas de estudo: a) da construção da identidade profissional, momento em que as identidades pessoal e profissional se constituem e se entrecruzam; b) da formação e a aprendizagem da docência, que nos permitem compreendê-la em seu caráter constitutivo; c) da realização, que se refere ao momento de prática em que a docência se instaura; d) e da permanência e continuidade, que faz com que se prossiga na profissão e se encontre significados para tal, apesar dos tantos desafios enfrentados. Nesse artigo, refletimos sobre os espaços-tempos de formação e de aprendizagem na docência. 


\section{A formação e a aprendizagem docente}

Mesmo revelando a amplitude dos espaços formativos vivenciados, os professores não ignoram a formação acadêmica obtida. Enquanto a maioria destaca o fato de a formação inicial ter "deixado a desejar" e/ou da pouca contribuição desta na sua constituição docente, há também quem a reconheça como fundamental. Mais precisamente, um total de 9 professores não poupa críticas à sua formação inicial, numa alusão ao principal fato: de que o curso não "ensina a ensinar".

É, então, apresentado o distanciamento existente entre a formação acadêmica e a realidade concreta do trabalho docente, inserida na dinâmica do cotidiano escolar, como um dos limites impostos à sua formação, implicando a necessidade de busca de conhecimento paralelo, conforme ressaltou a professora Bárbara, e ainda outros quatro professores:

Na universidade eles dão o mínimo. Para mim foi assim e eu sempre procurava buscar por fora, porque, se ficar só com aquilo, você sai e desiste da Educação Física [...]. Se você não fizer a sua parte, não correr atrás, não buscar, não estudar, não fazer tudo quanto é curso, não fizer um estágio, você sai dali e não consegue.

Soma-se à narrativa de Bárbara a de Bruno, que parece reclamar o papel formativo da Universidade e a melhoria da qualidade da formação inicial oferecida: "Logo que me formei eu falava que era pseudoprofessor porque muita coisa que eu tinha que fazer na escola não tinha nem visto no meio acadêmico [...]" (PROFESSOR BRUNO).

A análise feita por alguns professores se volta para o dilema da teoria e prática no decorrer da formação inicial. Se, para uns, o problema parece localizar-se no excesso de teoria trabalhada no curso, para outros, é ela o que falta. E, assim, os mesmos argumentos (de excesso e falta) são apresentados nas narrativas de outros professores ao tocarem na questão da dimensão prática que é desenvolvida no curso.

A professora Iara relativiza tal situação dizendo ter sido a formação "mais prática do que teórica". Contudo, também há ponderações e reconhecimentos, como o feito pela mesma professora. Desse grupo de nove professores, que não poupam críticas ao curso de Educação Física, há os que distinguem e relevam as contribuições advindas do período da graduação. Citam e enfatizam aqueles professores da universidade que, por meio de sua ação docente no nível superior de ensino, foram importantes para sua formação e demonstram sua admiração e respeito pelo trabalho que é/foi desenvolvido por eles.

Particularmente, as professoras Renata e Cláudia são as únicas que não apontam críticas negativas ao curso realizado. A primeira diz que sua graduação foi muito rica e suas aulas eram equilibradas entre teoria e prática. A segunda também reconhece que o curso somou, tanto em sua dimensão prática quanto teórica.

Nesse sentido, é o professor David que, rememorando a sua aproximação com o universo escolar, aborda um conjunto de percepções que podem ser traduzidas no que consideramos como concepção formativa ampliada, uma vez que incorpora os diversos espaços-tempos de formação: a formação institucional e a que a ela antecede (orientada pelos saberes da experiência), a autoformação (busca individual de conhecimentos) e aquela que é constituída no âmbito da prática docente: 
Ao entrar na escola, comecei a gostar. No início, eu me assustei, porque estava numa comunidade em que os alunos moram naqueles apartamentos pequenos, sem área de lazer, então, na escola, eles ficam 'bicho solto'. Foi logo no meu primeiro dia de aula da faculdade. [...] Foi aquilo: 'Meu Deus, o que é que eu fazia quando eu tinha essa idade na aula de Educação Física?'. Era uma turma de quarta série. Aí eu comecei a delegar atividades: 'Aqui pulando corda, aqui fazendo chute a gol, aqui virando estrelinha'. Foi uma coisa instintiva, porque eles não sabiam o que fazer, e nem eu [risos]. Eu aprendi a dar aula. Aprendi a fazer fazendo (PROFESSOR DAVID).

David, a se ver na condição de professor, parece experimentar, por iniciativa própria e não por demanda do curso, aquilo que Pimenta (2000, p. 20) assinala como um dos desafios postos ao curso de formação inicial: "[...] colaborar no processo de passagem dos alunos de seu ver o professor como aluno a seu ver-se como professor". Referimo-nos à relação de sua experiência de aluno com as ações do trabalho no contexto escolar, aliada à necessidade de buscas paralelas de estudo; ocasião em que David dá indícios do que Pimenta (2000) confere como um momento da construção de identidade de professor, no qual os saberes oriundos de sua experiência não bastam. Dessa maneira, sua narrativa congrega elementos que nos permitem ousar responder à indagação do como ele se fez professor.

A resposta coincide com a de Fonseca (2000), quando, em seus estudos sobre o ensino da disciplina História, questiona: "Como os(as) professores(as) se tornaram professores(as) de História?" E ela mesma responde: "Aprendendo e ensinando". Aprendizagem que David já iniciara na condição de aluno e, posteriormente, na de professor/estudante da licenciatura em Educação Física.

Apesar de identificarmos, nas narrativas dos sujeitos, diferentes percepções acerca da forma como cada um se apropriou dos saberes formativos em suas vidas, para David, como também para outros professores, a formação e a prática pedagógica não surgem como atividades distintas (FONSECA, 2000). A conclusão de que aprendeu a dar aula e a fazer fazendo, incide no que Arroyo (2000) aponta como possibilidade de entendimento de constituição docente, forjada sob o viés da aprendizagem.

O referido autor, também se contrapondo à ideia de docência como predestinação, significa o magistério como "[...] um modo de ser, uma produção histórica que traz as marcas de nossa formação social e cultural" (p. 125). Fala das mudanças ocorridas no sujeito, ao incorporar a condição de ser professor, e chama a atenção para o fato de que sabemos pouco sobre como acontecem os processos de internalização, aprendizagem e socialização da profissão docente. Fomenta sua discussão a partir das seguintes questões: qual o lugar de origem desse aprendizado? $\mathrm{Na}$ licenciatura? No exercício do magistério? Na imagem social veiculada na mídia e nas instituições nas quais estabelecemos vínculos?

Então responde às suas próprias indagações localizando, já nos primeiros contatos com os professores com os quais convivemos nos tempos de estudantes, desde a educação infantil, os elementos que indiciam o início do aprendizado dos professores que somos. Na fala do professor David essa aprendizagem torna-se explícita quando 'delega' em sua aula o que seus alunos deveriam fazer. É importante observar que não somente os conteúdos são rememorados por ele, mas também a forma de realizá-los. 
A figura do professor é uma das mais próximas e permanentes em nossa socialização, diferentemente de outras profissões, cujos saberes e aprendizagens ocorrem quase sempre no âmbito dos cursos de formação profissional específicos. Essa aprendizagem da docência se efetiva, nas palavras de Arroyo (2000, p. 125), por meio do "estágio-contágio entre humanos", numa alusão às relações estabelecidas com os professores que tivemos durante as nossas trajetórias de alunos, que perduram, acompanham e "contaminam" a forma de sermos professores no tempo presente. Para além dessas relações citadas, David considera ainda que, na condição de professores, aprendemos também com nossos alunos conteúdos (e não só isso) que passam a fazer parte de nosso repertório de saberes da docência.

Entretanto, as imagens e formas de ser professor que construímos não são explicadas com exclusividade pelas observações feitas pelos professores sobre convivências passadas, nem tampouco com as práticas específicas da profissão. Outras experiências e imagens são acrescentadas a esse aprendizado, influenciando a construção das identidades pessoal e profissional, conforme enfatiza Arroyo (2000).

$\mathrm{Na}$ Educação Física, as experiências com as práticas corporais são muito fortes na constituição da docência dos sujeitos professores, fato que pudemos verificar no estudo de Sanchotene (2007), quando busca compreender a relação existente entre as experiências vividas por professores de Educação Física em sua trajetória e a prática pedagógica no contexto de uma escola municipal de Porto Alegre-RS; bem como de Figueiredo (2004), quando afirma que as experiências incidem de modo significativo nos processos de construção e reconstrução de identidades no decorrer da formação, os quais estão, sobretudo, relacionados com a identificação que o aluno, antes de seu ingresso no curso, já tenha com determinados conteúdos, como esporte, dança, ginástica, etc.

A primeira autora citada considera o saber dos professores de Educação Física como "[...] um saber plural, que envolve aspectos relativos a suas experiências vividas em todas as sua dimensões: escolarização, vivências esportivas, graduação, prática na escola e formação permanente" (p. 87).

Dessa maneira, ela reduz o peso e a influência da formação inicial e continuada na prática efetiva dos professores na escola, atentando para as experiências realizadas por eles ao longo de seu ciclo de vida. A mesma aponta, então, um aspecto importante da imagem construída pelo professor sobre a sua prática docente: o gosto pessoal por determinada prática corporal, exercendo forte influência nas aulas que ministra, ora ampliando, ora limitando o leque de vivências dos alunos. Essa imagem é observada pela pesquisadora, quando chama a atenção para a prática pedagógica de um dos sujeitos de sua pesquisa. Ela diz que "[...] foi possível perceber que a sua vivência em Yoga e com a meditação influenciam fortemente a sua prática" (SANCHOTENE, 2007, p. 90), referindose tanto à escolha do conteúdo (a yoga) quanto às relações que a referida professora estabelece com seus alunos(as), as quais, segundo ela, são permeadas pelos "valores humanos".

A percepção dessa autora nos fez lembrar a fala do professor Áquila, marcada fortemente pelo gosto e identificação com a prática de esportes. Apresenta diversos episódios que vão desde aqueles ocorridos antes da realização do curso de Educação Física, até os que aconteceram durante ou mesmo após a sua realização, já na condição de professor e, em todas as ocasiões, o trabalho com as modalidades esportivas ganha centralidade.

Mereceu destaque o aprendizado relacionado com a conduta de professor, oriundo da experiência de aluno da graduação: 
[...] eu me preocupo muito de vir [dar aula] uniformizado [...]. Entendo [a importância de] um uniforme de professor de Educação Física: tenho que ter um tênis no pé, não posso vir dar aula de sapato, eu penso assim. Vejo colegas meus dando aula de sapato, de sandália, calça jeans e, particularmente, não concordo, porque eu aprendi assim desde a faculdade. Lá tinha uniforme: era o calção preto, a camisa branca, calça de malha e, quando esfriava, agasalho. Eu peguei essa época (PROFESSOR ÁQUILA).

Fontana (2005), assim como Arroyo (2000), toca na aprendizagem da docência, porém inserindo-se como sujeito de seu estudo e reconhecendo que a identidade de professora foi nela se constituindo mais como aprendizado do que como escolha. Essa autora percebe, nesse processo de aprendizagem, o movimento do "tornar-se sensível", cuja possibilidade de ordenamento ocorre nas relações que são estabelecidas com outros sujeitos e ao longo do tempo.

Dizer que também aprendemos a ser professor por meio das relações estabelecidas com os demais sujeitos sociais com os quais convivemos pode suscitar o entendimento equivocado da possibilidade de mera reprodução de práticas instituídas por outros. $\mathrm{O}$ fato de 'repetirmos' muita coisa que vemos/ouvimos/aprendemos não quer dizer que não produzamos modos singulares de agir no cotidiano escolar, pois, conforme apontado por Alves (2007), as experiências de docência nos são próprias, embora constituídas socialmente, uma vez que organizamos o que sabemos/aprendemos de acordo com as particularidades das situações concretas em que vivemos.

Construímos modos próprios de significar e realizar a nossa ação docente e cada ação habitual por nós desenvolvida "[...] tanto invoca todas as aulas assistidas e dadas — vividas como permite-nos criar algo novo, sempre" (ALVES, 2007, p. 64).

A dimensão do aprendizado advinda das relações ocorridas entre os sujeitos com os quais convivemos é abordada de forma mais enfática pela professora Renata, quando fala das trocas estabelecidas entre docentes, no exercício da profissão: “[...] sempre aprendi muito no bate-papo de corredor com colegas de área [...]. O que eu aprendi nessa escola, o professor que me ensinou trouxe de outra escola, e eu já estou levando pra outra. [...] e chamo de conversinha de corredor" (PROFESSORA RENATA).

Renata toca na questão da aprendizagem docente constituída no âmbito da escola como espaço formativo e das relações, ou 'trocas', realizadas entre os pares - neste caso, os sujeitos professores. Essa percepção remete ao que Hargreaves (1998) define de "regiões frontais" e "regiões de retaguarda" da vida social ${ }^{47}$. As primeiras são aquelas nas quais as pessoas estão "em cena", e a associa aos professores em atuação na sala de aula, momento em que necessitam "[...] monitorizar e regular a sua conduta, de modo a "manterem as aparências"' (p. 122). Já as regiões de retaguarda surgem como "as áreas de bastidores", vistas como os espaços em que se permitem “[...] o relaxamento, o alívio e a fuga às tensões e exigências destas performances de "palco"” (p. 122).

47 Ideia essa desenvolvida por Goffman (1959) apud Hargreaves (1998, p. 122), como referência para suas análises. 
São pelo autor entendidas como o tempo de intervalo dos professores na escola, como o recreio, por exemplo.

Ele destaca, também, a importância da região de retaguarda para o trabalho docente, pois, além de ajudar no alívio das tensões, pelo afastamento das atribuições características da região frontal, "[...] promovem relações informais que criam confiança, solidariedade e camaradagem entre os professores". A estas últimas somamos a oportunidade de os professores promoverem aprendizagens significativas conforme as ressaltadas pela professora Renata, quando fala de suas "conversas de corredor".

Entretanto, os professores, ao utilizarem o seu tempo de descanso de sala de aula (como o recreio e o horário de almoço) para a realização de atividades que envolvem a sua função docente, por exemplo, quando Renata de maneira informal constitui esse espaço em um local de formação, os professores acabam por conduzir, de certo modo, um momento que seria típico de uma região frontal (a formação/aprendizagem) para o panorama da região de retaguarda.

Se a professora Renata é uma dentre aqueles que vivenciam e reconhecem a possibilidade de aprendizado por meio de uma relação generosa entre colegas professores com os quais convive, o mesmo não é observado nas narrativas de outros cinco professores da pesquisa. Estes trouxeram à tona o contrário do que aponta Renata, aproximando do que Azevedo (2004) diz acarretar no isolamento profissional.

Tomamos, então, a fala da professora Iara, em que a ocorrência dessa situação pode ser visualizada, quando assim reconhece esse contexto de relações entre professores:

[...] eu acho um espaço muito egoísta. Egoísta para confraternizar as questões do conhecimento [...]. Às vezes eu começo o trabalho, penso que é um projeto, como foi decidido em grupo, e acabo fazendo sozinha. As pessoas vão tirando o corpo fora, porque é mais fácil, não dá trabalho [...]. É muito fácil a pessoa falar eu não concordo com isso e não vou fazer mas aí não faz nada! Então eu acabo fazendo sozinha, mas isso vai cansando. Só que eu não consigo desistir, sabe? (PROFESSORA IARA).

Iara vai além do egoísmo que provoca o isolamento de professores de uma mesma instituição escolar. Sutilmente, traz à tona outra realidade existente no âmbito das relações na escola: a dos que optam por isolar-se numa atitude compreendida por ela como "descompromisso profissional", quando fala dos que tiram o "corpo fora", e dos que nada fazem.

A indignação com o "descompromisso profissional" no magistério também surge na fala de mais quatro professores. Tomaremos o exemplo da narrativa da professora Bárbara que, incomodada, não só com os colegas da própria área, mas também os incluindo, diz:

[...] eu não sei se eu devia falar disso, mas eu sempre vi e continuo vendo pessoas [educadores] preocupadas com o dinheiro, indo para a escola pra marcar presença e receber seu salário no final do mês. Não estão nem aí para fazer um trabalho, para dar aula. [...] não fazem nada! Ou, quando faz, não é uma coisa planejada, não tem um plano, um objetivo daquilo [...]. Tem profissionais bons! Aqui na escola mesmo, a gente vê que tem! Mas muitos, infelizmente... não dá pra falar muito bem não (PROFESSORA BÁRBARA). 
As duas professoras citadas, apesar de apontarem a questão do egoísmo e da atitude "mercenária" presentes nos sujeitos com os quais convivem no espaço educacional, reconhecem a existência de "brechas" e possibilidade de trocas, quando distinguem aqueles professores comprometidos e que "querem fazer".

A professora Cláudia, ao falar sobre a escola como espaço formativo, considera que "[...] infelizmente é cada um por si e Deus por todos!", indiciando que, em seu contexto de trabalho, não (re)conhece essa possibilidade, percebendo-se isolada na realização da profissão. Já a professora Nívea, revela as parcerias que consegue estabelecer na escola, e também a sua necessidade de participar de momentos, como os Conselhos de Classe, as reuniões de pais e/ou de professores, e demais ocasiões que envolvem o coletivo da escola. Considera, ainda, o "campo de forças" no qual se insere essa participação ou não, quando diz que o trabalho integrado e a possibilidade de participar dessas ocasiões, depende também da iniciativa de o professor reivindicar e buscar o seu espaço e que, para assegurá-lo, é necessária uma disputa que envolve poder, mas, sobretudo, a vontade de participar.

Ao tocar nas características da profissão docente, Morgado (2005) considera o isolamento profissional como uma delas e o associa ao individualismo dos professores. Atribui à arquitetura das escolas, com suas salas individualizadas, à falta de espaços coletivos e "polivalentes", e à própria organização curricular (disciplinarização do conhecimento), os motivos que favorecem tal ocorrência.

Esse mesmo autor concorda com a posição de Hargreaves (1998), para quem a postura individualista dos docentes desencadeia conseqüências negativas tanto para o seu desenvolvimento profissional quanto para a melhoria das práticas educativas e o desenvolvimento de projetos de mudança que se fazem necessários no campo educacional.

Afirmações desses autores alertam que no âmbito do desenvolvimento das escolas, do desenvolvimento profissional dos professores e da mudança educativa, a cultura do individualismo apresenta-se como uma heresia crucial. O individualismo desponta como uma ameaça ou obstáculo para o desenvolvimento profissional e de objetivos educativos compartilhados. No entanto, advertem para a necessidade de não se considerar que todo individualismo do professor é perverso, quando a ele (ao individualismo) se associam e diferenciam as posturas de solidão e de isolamento.

Supomos que um desses momentos benéficos a que Hargreaves (1998) se refere tem a ver com a busca individual dos professores, aqui entendida sob o ponto de vista da autoformação. Tomamos como exemplo o entendimento da professora Luiza, a qual destaca a necessidade de dar continuidade ao processo formativo acadêmico: "[...] continuo comprando e lendo livros da área". Ao mesmo tempo, emite uma opinião que considera que "[...] a formação continuada, parte principalmente do próprio interesse [do sujeito] de (re) aprender".

Assim como Luiza, a professora Sofia também chama a atenção para esta dimensão autoformativa da constituição docente:

Eu me pego muitas vezes na minha prática tomando determinadas atitudes que depois eu falo: "Não acredito que eu fiz isso!". Mas o bom..., porque quando você tem minimamente alguns pressupostos você consegue refazer isso. Eu acho que o ser professor é isso, é você ser capaz de, constantemente, se refazer, se ver no processo, se reconstruir a cada dia, a cada momento, porque a prática é uma coisa assim [...] todo instante tem surpresa, tem coisa nova (PROFESSORA SOFIA). 
Entretanto, ressaltamos uma particularidade na fala de Sofia, quando ela apresenta e situa a dimensão formativa presente no âmbito de sua atuação pedagógica no contexto escolar. Indicia a realização de uma prática reflexiva, que incide no que Pimenta (2000) atribui como o espaço em que os professores reelaboram os seus saberes quando postos em confronto com suas experiências práticas no cotidiano escolar. Diz a autora que "[...] é nesse confronto e num processo coletivo de troca de experiências e práticas que os professores vão constituindo seus saberes como praticum, ou seja, aquele que constantemente reflete na e sobre a prática" (p. 29).

Em síntese, pode-se dizer que em meio a esse turbilhão de sentidos e subjetividades inerentes à docência, registrados aqui e advindos dos espaços formativos vivenciados, das experiências com práticas corporais, das relações estabelecidas com outros sujeitos da escola, dos individualismos, dos isolamentos, dos compartilhamentos, da prática pedagógica, a docência em Educação Física vai se constituindo cotidianamente.

\section{Considerações Pertinentes}

Pudemos problematizar e experimentar outras formas de olhar, ou melhor, de reparar a profissão professor de Educação Física e, dessa maneira, abrir espaços que nos permitem vislumbrar possibilidades de entendimento e de intervenção nos processos de formação e de prática docente dessa área específica.

Aproximamo-nos dos lugares praticados pelos professores, mostrando as marcas que os constituem, suas experiências, os seus 'possíveis' e, também, os desafios que ao emergirem em suas falas, ora os impulsionam, ora os desestimulam a permanecer na profissão. Pudemos, sobretudo, compreender o processo de construção da docência sob a perspectiva da aprendizagem, realizada nos múltiplos espaços sociais e nas constantes relações estabelecidas com os sujeitos com os quais convivemos.

Compreendemos que a realização deste estudo congregou, em grande medida, um caráter formativo, tanto em nós quanto em todos que nele se implicaram de algum modo, conforme os diversos autores com os quais dialogamos defendem. Referimo-nos, em especial, aos sujeitos com os quais interagimos e que agora tornamos públicas muitas das suas, e nossas, experiências, histórias e trajetórias vividas na constituição do ser professor de Educação Física.

Interações que tentamos realizar durante todas as etapas da pesquisa, mas que, em razão do tempo e das outras atribuições que a vida nos imprime, limitaram uma aproximação mais efetiva com os sujeitos e a possibilidade de acentuar ainda mais o caráter formativo/reflexivo desse tipo de investigação.

Para concluir este momento de estudo, chamamos mais uma vez à interlocução Arroyo (2000), juntamente com os demais autores sujeitos colaboradores da pesquisa, segundo os quais não nascemos mas "aprendemos a ser professor"; não temos uma única imagem, como muitas vezes nos veem, enquadram e dizem; somos múltiplos e plurais. 


\title{
TEACHER TRAINING AND LEARNING IN SCHOOL PHYSICAL EDUCATION
}

\begin{abstract}
This study aims to understand how physical education teachers constitute themselves as teachers at school, amid many different meanings and singularities, considering the school as a privileged locus in which teaching is constituted. It has been carried out by 12 Elementary School teachers . The study makes use of three different tools to collect information: a survey, a memorial and a narrative interview. In the midst of recurrences and singularities of the narratives, it addresses the following topics of analysis: a) construction of professional identity; b) teacher training and learning; c) moment of practice in which teaching is established; and d) permanence and continuity.
\end{abstract}

Keywords: Physical Education. Training. Teachers learning.

\section{FORMACIÓN Y EL APRENDIZAJE EN LA DOCENCIA EN EDUCACIÓN FÍSICA}

\section{Resumen}

Busca comprender cómo los profesores educación física constituyen docentes en la escuela, entre los diferentes sentidos y singularidades, considerando a la escuela como un lugar privilegiado en el que se establezca la docencia. Fue desempeñado por 12 profesores que trabajan en la escuela primaria. Utiliza tres instrumentos para recoger información: el cuestionario, el memorial, la entrevista narrativa. En medio de las recurrencias y singularidades de las narrativas, visualiza temas para el análisis: a) construcción de la identidad profesional; b) la formación de la aprendizaje en la enseñanza; c) el tiempo de práctica en la que la docencia se construye; d) permanencia y continuidad.

Palabras-clave: Educación Física. Formación. Aprendizaje Docente.

\section{Referências}

ALVES, N. Nós somos o que montamos: a narrativa de si como prática de formação. Programa 5, 2007.

Disponível em:<htttp://www.tvebrasil.com.br/salto/boletins2007/hvfp/070326_historias.doc>.Acesso em: 9 maio 2007.

ARROYO, M. Ofício de mestre: imagens e auto-imagens. Petrópolis, RJ: Vozes, 2000.

AZEVEDO, J. G.; ALVES, N. (org.). Formação de professores: possibilidades do imprevisível. Rio de Janeiro: DP\&A, 2004.

AZEVEDO, J. G. De abobrinhas a roca de figurinhas. In: ; ALVES, N. (org.). Formação de professores: possibilidades do imprevisível. Rio de Janeiro: DP\&A, 2004. p.1127.

FIGUEIREDO, Z. C. C. Experiências Sociais no Processo de Formação Docente em Educação Física. 2004. 159 p. Tese (Doutorado) — Faculdade de Educação, UFMG, Belo Horizonte, 2004. 
FONSECA, S. G. O prazer de viver e ensinar História. In: VASCONCELOS, G. A. N. (org.). Como me fiz professora. Rio de Janeiro: DP\&A, 2000. p. 113-136.

FONTANA, R. A. C. Como nos tornamos professoras? Belo Horizonte: Autêntica, 2005.

HARGREAVES, A. Os professores em tempos de mudança. Portugal: McGrraw, 1998.

MORGADO, J. C. Currículo e profissionalidade docente. Porto: Porto, 2005.

PIMENTA, S. G. P. Formação de professores: identidade e saberes da docência. In: (org.).

Saberes pedagógicos e atividade docente. São Paulo: Cortez, 2000. p. 1534.

SANCHOTENE, M. U. A elação entre as experiências vividas pelos professores de Educação Física e a sua prática pedagógica: um estudo de caso. 2007. Dissertação (Mestrado em Ciências do Movimento Humano) - Programa de Pós-Graduação em Ciências do Movimento Humano, Universidade do Rio Grande do Sul, Porto Alegre, 2007.

TEIXEIRA, I. A. C.; PÁDUA, K. C. Virtualidades e alcances da entrevista narrativa. In: Congresso Internacional de Pesquisa (Auto)Biográfica, 2, 2006, Salvador. Anais... Salvador: CIPA, 2006.

Recebido em: 24/06/2013

Revisado em: 09/12/2013

Aprovado em: 25/04/2014

Endereço para correspondência:

Zenólia Christina Campos Figueiredo zenoliavix@gmail.com

Universidade Federal do Espírito Santo, Centro de Educação Física e Desportos Av. Fernando Ferrari, s/n ${ }^{\circ}$ - Goiabeiras 29000-300 - Vitória, ES - Brasil 